\title{
Detección de Neonectria fuckeliana en Chile, asociado a cancros y malformaciones fustales en plantaciones de Pinus radiata
}

\author{
Detection of Neonectria fuckeliana in Chile associated to stem cankers and malformations \\ in Pinus radiata plantations
}

\author{
Rodrigo Morales R \\ Universidad Austral de Chile, Facultad de Ciencias Forestales, Instituto de Silvicultura, casilla 567, Valdivia, Chile, \\ tel.: 56-63-293618,rmorales@uach.cl
}

\begin{abstract}
SUMMARY
The presence of the fungus Neonectria fuckeliana in Pinus radiata plantations in the commune of Toltén, Region of Araucanía, Chile was reported. The presence of cankers and kink-stem of the trees were observed as symptoms of infection which started from the areas of healing of pruning. About $80 \%$ of the trees in the stands surveyed presented damage. On the bark of the cankered stems, we observed abundant fruiting bodies growing in a clumped pattern presenting spherical forms and a reddish brown color; which were analyzed in the laboratory. According to microscopy and taxonomic keys of these structures, we found that they agreed with the perithecia $N$. fuckeliana; the disease characterized by producing stem cankers and malformations on stems, such as those described in coniferous species. The present study is the first report of damage caused by $N$. fuckeliana in P. radiata plantations in the country, thus starting studies to address this problem arises as urgent.
\end{abstract}

Key words: cankers, malformations, stems, Pinus radiata, Neonectria fuckeliana, pathogen, pruning.

\section{RESUMEN}

Se reporta la presencia del hongo Neonectria fuckeliana en plantaciones de Pinus radiata en la comuna de Toltén, Región de La Araucanía, Chile. Se constató la presencia de cancros y torceduras en los fustes de los árboles, sintomatología que se inicia desde las zonas de cicatrización de poda. El daño se presentó en aproximadamente el $80 \%$ de los árboles evaluados. Sobre la corteza de los fustes que presentaban cancros se observaron abundantes fructificaciones creciendo de manera agrupada, de formas esféricas y de color rojizo a marrón. Los estudios en laboratorio comprobaron que correspondían a peritecios del hongo $N$. fuckeliana, patógeno descrito en la literatura como causante de cancros y malformaciones fustales en $P$. radiata y otras especies de coníferas. El presente estudio corresponde al primer reporte de $N$. fuckeliana en plantaciones de $P$. radiata en el país. De esta manera se propone el inicio de estudios y recomendaciones para abordar este problema.

Palabras clave: cancros, malformaciones fustales, Pinus radiata, Neonectria fuckeliana, patógeno, poda.

\section{INTRODUCCIÓN}

Pinus radiata D. Don es la especie de mayor importancia económica para el sector forestal chileno, debido a la creciente exportación de productos de la industria de celulosa, aserrío y tableros. Actualmente las plantaciones de $P$. radiata en Chile abarcan un total de 1,4 millones de hectáreas, concentradas principalmente desde la VII a X Regiones (INFOR 2008).

A fines de 2008 se detectaron anormalidades en rodales de $P$. radiata ubicados en el sector costero de la comuna de Toltén, Región de La Araucanía, Chile. Los árboles presentaban depresiones y muerte del tejido cortical (cancros) a lo largo del fuste y un torcimiento del árbol. Reportes efectuados en Europa y Estados Unidos indican daños similares causados por especies del género Nectria en coníferas y latifoliadas (Peace 1962, Funk 1981, Hansen y Lewis 2003). Entre estas especies, Neonectria fuckeliana (sin. Nectria fuckeliana) produce daños de importancia económica sobre coníferas, principalmente en los géneros Abies, Larix, Pinus y Picea (Peace 1962, Schulzt y Parmeter 1990, Dick et al. 2006, Power y Ramsfield 2007, Dick y Crane 2009). El presente trabajo tuvo por objetivo determinar el agente causal de esta anormalidad sanitaria sobre $P$. radiata observada en Chile.

\section{MÉTODOS}

El estudio se realizó a fines de octubre de 2008 en un predio localizado en la comuna de Toltén, Región de La Araucanía, con elevación entre 80 y 300 m s.n.m. La 
topografía del sector es de lomajes y cerros, de suelos profundos a moderadamente profundos y drenaje moderado, derivados de esquistos metamórficos y sedimentos marinos (zona de crecimiento 0-7-3 descrita por Schlatter et al. 1995). La precipitación anual de la zona es 1.994 $\mathrm{mm}$ y las temperaturas máxima y mínima promedio de $21^{\circ}$ y $5^{\circ} \mathrm{C}$, respectivamente, y una humedad relativa del aire promedio de $83 \%$ anual (Santibáñez y Uribe 1993).

Las evaluaciones fueron efectuadas en dos rodales contiguos de $P$. radiata de 7 y 15 años de edad (39 $16^{\circ} 26^{\prime \prime}-39^{\circ}$

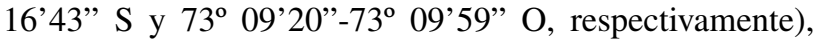
abarcando una superficie aproximada de 150 ha. El rodal de siete años tenía una densidad de 800 árboles/ha, DAP medio $18 \mathrm{~cm}$ y altura de $11 \mathrm{~m}$, y fue podado y raleado aproximadamente dos años antes del estudio. En el rodal de 15 años la densidad era de 400 árboles/ha, DAP medio $32 \mathrm{~cm}$, altura $20 \mathrm{~m}$ y presentaba dos raleos y dos podas. La última poda fue efectuada alrededor de cinco años atrás y en ambos rodales abarcó el $100 \%$ de los árboles. La caracterización del daño se basó en información de la administración del predio ${ }^{1}$ y se verificó mediante dos parcelas de $150 \mathrm{~m}^{2}$ ubicadas de manera aleatoria dentro de cada rodal, donde sólo se evaluó la presencia de cancros y fructificaciones (incidencia del agente). Del interior de las parcelas se extrajeron trozos de cortezas de los árboles (fustes) con presencia de cancros, los cuales presentaban fructificaciones, material que se llevó a laboratorio para su estudio. Para la determinación del agente causal se realizaron observaciones y mediciones microscópicas del diámetro de las fructificaciones, midiendo un total de 50 unidades seleccionadas aleatoriamente del total de las muestras colectadas. Igual número y elección se utilizó para las mediciones de esporas, considerando su largo y ancho respectivamente. Se emplearon claves taxonómicas y bibliografía específica para su identificación (von Arx 1962, Funk 1981, Brayford et al. 2004). Los análisis se realizaron en el Laboratorio de Patología Forestal de la Universidad Austral de Chile.

\section{RESULTADOS}

Los árboles de ambos rodales presentaron igual sintomatología, depresiones y necrosis en el fuste a nivel de corteza (cancros). Tales cancros se originaban a partir de los verticilos podados de los árboles, lugar donde se observaban las cicatrices de poda (figura $1 \mathrm{~A}, \mathrm{~B}, \mathrm{C}$ ). El $80 \%$ de los árboles de cada rodal presentó este daño, coincidiendo con la evaluación del administrador. Dependiendo del desarrollo del cancro, se desarrollaron malformaciones a modo de torceduras espiraladas en los fustes, producto de la muerte de algunas zonas de tejido, mientras que el tejido no afectado continuaba en crecimiento de manera

1 Sr. Ricardo Urra, administrador del predio. Comunicación personal. normal, dándole en algunos árboles esta característica particular de daño (figura $1 \mathrm{D}, \mathrm{E}, \mathrm{F}, \mathrm{G}$ ).

En los estudios de laboratorio se estableció que las estructuras de fructificación correspondían a conjuntos de peritecios, de forma esférica globosa a periforme, de paredes gruesas y superficies lisas, con un ostíolo apical. Sus dimensiones variaron entre 200 y $350 \mu \mathrm{m}$ (figura 1 $\mathrm{H}, \mathrm{I})$, con una media de $300 \pm 40 \mu \mathrm{m}$ de diámetro $(\mathrm{n}=50)$. Los ascos de forma cilíndrica presentaron en su interior ocho ascosporas bicelulares, hialinas, gutuladas, algo fusiformes y levemente acinturadas en la porción central donde se ubica el tabique. Las dimensiones de los ascosporas fueron de $14,1 \pm 1,2 \mu \mathrm{m}$ de largo y de $6,05 \pm 0,5$ $\mu \mathrm{m}$ de ancho $(\mathrm{n}=50)$, con un rango entre 11 y $15,5 \mu \mathrm{m}$ (figura $1 \mathrm{~J}, \mathrm{~K}$ ).

\section{DISCUSIÓN}

Por las características de los síntomas observados en los árboles de ambos rodales (figura 1) y apoyado por los estudios de laboratorio, el agente asociado a los cancros correspondió al hongo Neonectria fuckeliana (C. Booth) Castl. et Rossman comb. nov. sinónimo: Nectria fuckeliana (C. Booth) y estado anamorfo Cylindrocarpon cylindroides Wr. var. tenue Wr. (Dick y Crane 2009, Castlebury et al. 2006). Este patógeno es caracterizado por causar cancros y malformaciones fustales en especies de coníferas, destacándose los géneros Abies, Larix, Pinus y Picea (Gäumann 1951, Peace 1962, Funk 1981, Schulzt y Parmeter 1990, Brayford et al. 2004, Dick et al. 2006, ENSIS 2008). Su presencia ha sido reportada en EE.UU., Canadá, Francia, Austria, Alemania, Inglaterra, Suiza y Nueva Zelandia (Brayford et al. 2004).

Peace (1962) señala que este patógeno se caracteriza por ingresar principalmente por heridas e inserciones de ramas (verticilos) cuando hay muerte de ramas. En Europa se señala que el hongo ingresaría por lesiones producidas por efecto de heladas (Gäumann 1951). En plantaciones de $P$. radiata en Nueva Zelandia se determinó que el ingreso principal de $N$. fuckeliana en árboles es a través de heridas ocasionadas por podas, produciéndose cancros alrededor de la herida, los que se prolongan a lo largo del fuste y causan malformaciones fustales a modo de torceduras y espiralamientos (Dick et al 2006, ENSIS 2008).

Durante la década de 1990 las plantaciones de $P$. radiata en Nueva Zelandia fueron afectadas por la presencia de este hongo patógeno. Se presume que ingresó en ese país durante la década de 1980 y actualmente $N$. fuckeliana afecta alrededor de 140.000 hectáreas de plantaciones de $P$. radiata en la Isla del Sur, Dunedin y al sur de Canterbury, ocurriendo con mayor incidencia en la zona costera. Las empresas forestales de la región afectada estiman que hasta un $15 \%$ de los árboles desarrollan cancros después de la poda. Estudios señalan que el daño del hongo comenzaría principalmente a causa de la herida por esta práctica, lugar 


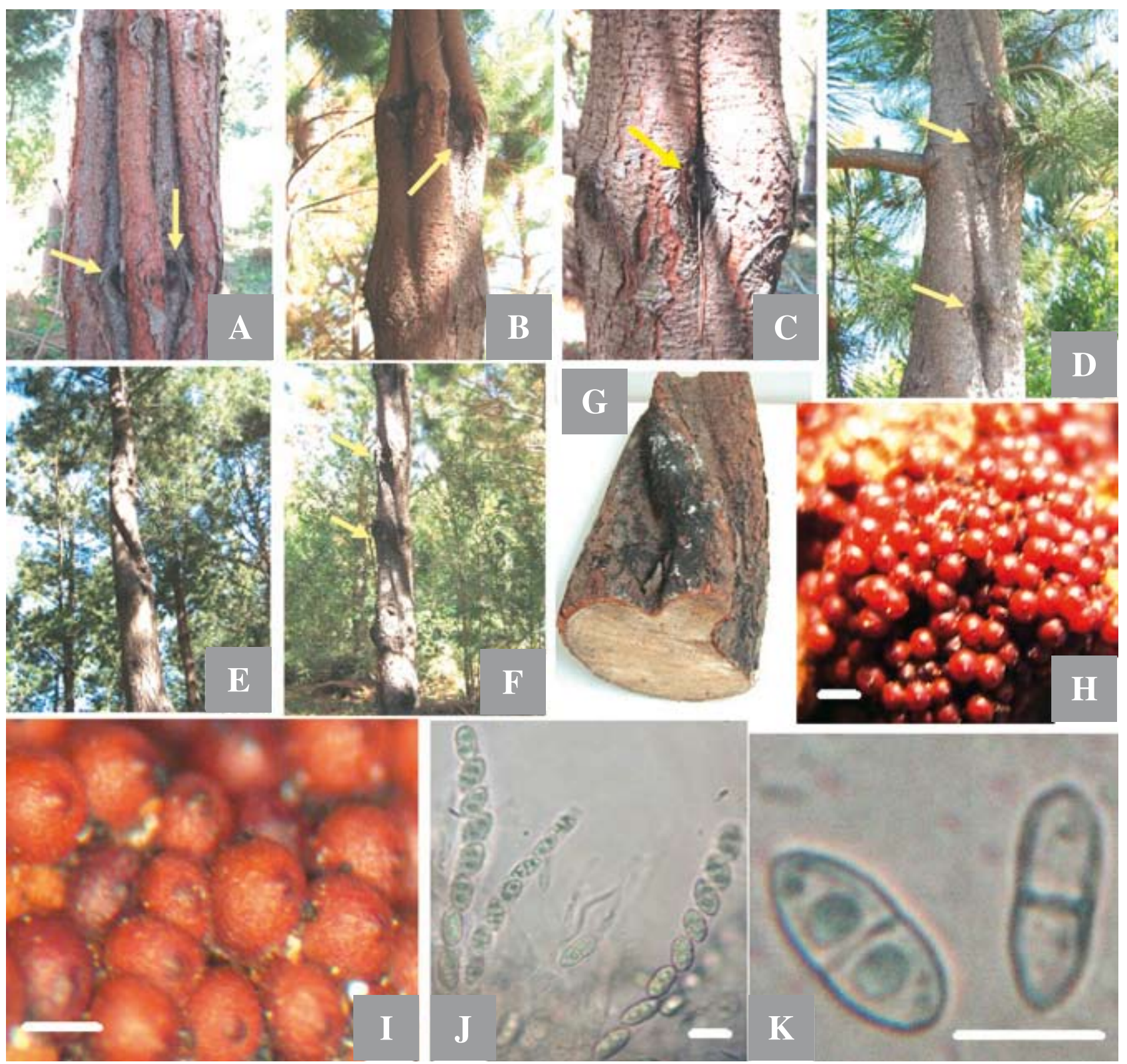

Figura 1. Síntomas y signos de la presencia de Neonectria fuckeliana sobre P. radiata: A-B-C, presencia de cancros fustales en diferentes magnitudes. D-E-F-G, torceduras fustales producto de los cancros (las flechas indican muñones de ramas podadas). H-I, agrupaciones de peritecios de $N$. fuckeliana (la barra de color blanco representa aproximadamente $250 \mu \mathrm{m}$ ). J-K, detalle microscópico de ascos y ascosporas característicos de $N$. fuckeliana (la barra de color blanco representa aproximadamente $10 \mu \mathrm{m}$ ).

Symptoms and signs of the presence of Neonectria fuckeliana on P. radiata: A-B-C, presence of stem cankers in different magnitudes. D-E-F-G, kink-stem product of stem cankers (arrows indicate stubs of pruned branches). H-I, groups perithecia $N$. fuckeliana (white bar represents approximately $250 \mu \mathrm{m}$ ). J-K, microscopic details of ascus and ascospores characteristic of $N$. fuckeliana (white bar represents approximately $10 \mu \mathrm{m})$.

donde comenzaría la infección y posterior sintomatología de cancros en la temporada siguiente (ENSIS 2008, Dick y Crane 2009). A pesar de que el volumen de pérdida de madera individual por árbol puede ser bajo, $N$. fuckeliana afecta la parte más valiosa de los árboles (primera troza), descalificando o generando la pérdida de la troza basal (ENSIS 2008).
Las investigaciones de campo referentes al manejo de este patógeno no han arrojado aún información suficiente respecto al control (Dick et al. 2006, Power y Ramsfield 2007, ENSIS 2008). Los ensayos establecidos para determinar el efecto de la silvicultura apuntan a buscar un período adecuado de poda para evitar la infección. Esta actividad realizada en invierno se asocia a mayor infección en los 
árboles en comparación con la poda en verano, siendo desconocidas las razones de tal resultado (ENSIS 2008). Desde el año 2007 en Nueva Zelandia está en marcha un proyecto para evaluar el daño por este patógeno a través del tiempo, ya que se estima que gran cantidad de los árboles que no presentan signos de infección aparente se encontrarían infectados. Esta hipótesis concuerda con los resultados crecientes de incidencia de $N$. fuckeliana en plantaciones de $P$. radiata (Turner et al. 2007). La incidencia también guarda relación con el tamaño de los muñones de poda y se determinó que árboles con muñones menores a $30 \mathrm{~mm}$ de diámetro rara vez presentan cancros. Otras investigaciones para el control de la enfermedad incluyen poda de ramas de menor diámetro, pinturas con compuestos fungicidas para formar una barrera de ingreso al hongo, aumento de la densidad de plantación para limitar el crecimiento de ramas laterales y aplicaciones de bioprotectores. Sin embargo, ninguno de estos ensayos ha logrado un control adecuado (Dick et al. 2006).

El presente trabajo corresponde al primer reporte de daños causados por $N$. fuckeliana en plantaciones de $P$. radiata en Chile. $\mathrm{Al}$ respecto, cabe destacar que los daños ocasionados por este patógeno pueden ocurrir principalmente en aquellas plantaciones con esquema de manejo (podas) para la obtención de madera libre de nudos. A pesar de que el volumen de pérdida de madera por árbol puede ser bajo, $N$. fuckeliana descalifica por su daño la primera troza de mayor valor (ENSIS 2008). Por información de la administración del predio ${ }^{2}$, se estima que el tiempo de ocurrencia de síntomas del daño sería al año siguiente a la poda. Ello coincidiría con estudios que señalan que el daño comenzaría principalmente a causa de la herida por esta práctica, con la infección y posterior formación de cancros en la temporada siguiente (Dick et al. 2006). De esta manera, se puede inferir que en estos rodales el patógeno se encontraría presente desde la última poda del rodal de 15 años, es decir, dentro de los últimos cinco años, y probablemente las condiciones ambientales de la zona (temperatura, humedad relativa, época de las heridas de poda) fueron favorables para su infección.

Frente a esta situación se debe comenzar a trabajar en investigaciones básicas y aplicadas que permitan aminorar el daño a futuro. Se requieren enfoques para determinar épocas de poda para evitar infección en esa zona, ciclo biológico y epidemiológico del patógeno y medidas preventivas con el fin de mitigar daños y poder convivir con esta enfermedad.

2 Sr. Ricardo Urra, administrador del predio. Comunicación personal.

\section{AGRADECIMIENTOS}

Al profesor Dr. Eduardo Valenzuela (Instituto de Microbiología, UACh) y a la Tecnóloga Médico Sra. Isabel Vives (Instituto de Silvicultura, UACh) por su colaboración en la ratificación taxonómica del patógeno, al Instituto de Silvicultura de la UACh por su financiamiento para que las imágenes fueran editadas en color, y a los Ingenieros Forestales Felipe Leiva y Eduardo Molina por su colaboración en las prospecciones en terreno.

\section{REFERENCIAS}

Brayford D, B Honda, F Mantiri, G Samuels. 2004. Neonectria and Cylindrocarpon: the Nectria mammoidea group and species lacking microconidia. Mycologia 96: 572-597.

Castlebury L, A Rossman, A Hyten. 2006. Phylogenetis relationships of Neonectria/Cylindrocarpon on Fagus in North America. Canadian Journal Botanic 84: 1417-1433.

Dick M, P Crane. 2009. Neonectria fuckeliana is pathogenic to Pinus radiata in New Zealand. Australasian Plant Disease 4: 12-14.

Dick M, L Bulman, P Crane. 2006. Nectria fuckeliana infection of Pinus radiata in New Zealand: Proceedings of the 53rd Western International Forest Disease Work Conference, Jackson USA, 26-30 september 2005. Consultado 20 diciembre 2008. Disponible en http: //nzpps.org/journal/59/ nzpp59_369.pdf.

Funk A. 1981. Parasitic microfungi of western trees. Canadian Forestry Service, Pacific Forest Research Center. Victoria, Canada. Editorial Pacific Forest Research Center. 190 p.

Gäumann E. 1951. Pflanzliche Infektionslehre: Lehrbuch der allgemeinen Pflanzpathologie für Biologen, Landwirte, Förste und Pflanzenzüchter. Basel, Suiza. Editorial Birkhäuser Bansel. 681 p.

Hansen E, K Lewis. 2003. Plagas y enfermedades de coníferas. The American Phytopathological Society. Madrid, España. Ediciones Mundi-Prensa. $101 \mathrm{p}$.

INFOR (Instituto Forestal, CL). 2008. Estadísticas 2004-2005: Bosques plantados por especies según región. Consultado 6 nov. 2008. Disponible en http://www.infor.cl/webinfor/estadisticas Forestales/2004_2005/Recursos_Forestales/bso.

ENSIS. 2008. Nectria flute canker. Consultado 20 de noviembre. 2008. Disponible en http://www.ensisjv.com/ResearchCapabilities Achievements/ ForestHealthBiosecurityandFire/ForestPestFactSheet/ Nectriaflutecanker/tabid/433/Default.aspx.

Peace TR. 1962. Pathology of trees and shrubs. With special reference to Britain. Oxford University Press, Great Britain. $751 \mathrm{p}$.

Power M, T Ramsfield. 2007. Detection of Nectria fuckeliana in wood cores from pruned and un-pruned Pinus radiata. Second year results - February 2007. ENSIS. Reporte no publicado $\mathrm{N}^{\circ} 41611$.

Santibáñez F, J Uribe. 1993. Atlas Agroclimático de Chile: Regiones VIII y IX. Universidad de Chile, Santiago, Chile. Facultad de Ciencias Agrarias y Forestales, Laboratorio de Agroclimatología. 66 p. 
Schulzt ME, J Parmeter. 1990. A canker disease Abies concolor caused by Nectria fuckeliana. Plant Dis. 74: 178-180.

Schlatter J, V Gerding, H Huber. 1995. Sistema de ordenamiento de la tierra: herramienta para la planificación forestal en la X Región. Universidad Austral de Chile, Facultad de Ingeniería Forestal, Valdivia, Chile. 93 p. (Serie Técnica).

Turner J, J Buongiorno, S Zhu, JP Prestemon, R Li, LS Bulman. 2007. Modelling the impact of the exotic forest pest Nectria on the New Zealand forest sector and its major trading partners. New Zealand Journal of Forestry Science 37 (3): 383-411.

von Arx JA. 1962. Beiträge zur Kryptogamenflora der Scheiz: Die Gattungen der didymosporen Pyrenomyceten. Berna, Suiza. Editorial Warer. 922 p.

Recibido: 16.12 .08

Aceptado: 25.05 .09 